\title{
A First Comparative Study of Oesophageal and Voice Prosthesis Speech Production
}

\author{
Massimiliana Carello $^{1}$ and Mauro Magnano ${ }^{2}$ \\ ${ }^{1}$ Dipartimento di Meccanica, Politecnico di Torino, Corso Duca degli Abruzzi 24, 10129 Torino, Italy \\ ${ }^{2}$ Ospedali Riuniti di Pinerolo, A.S.L. TO3, Via Brigata Cagliari 39, 10064 Pinerolo, Torino, Italy
}

Correspondence should be addressed to Massimiliana Carello, massimiliana.carello@polito.it

Received 31 October 2008; Revised 2 March 2009; Accepted 30 April 2009

Recommended by Juan I. Godino-Llorente

The purpose of this work is to evaluate and to compare the acoustic properties of oesophageal voice and voice prosthesis speech production. A group of 14 Italian laryngectomized patients were considered: 7 with oesophageal voice and 7 with tracheoesophageal voice (with phonatory valve). For each patient the spectrogram obtained with the phonation of vowel /a/ (frequency intensity, jitter, shimmer, noise to harmonic ratio) and the maximum phonation time were recorded and analyzed. For the patients with the valve, the tracheostoma pressure, at the time of phonation, was measured in order to obtain important information about the "in vivo" pressure necessary to open the phonatory valve to enable speech.

Copyright ( $) 2009$ M. Carello and M. Magnano. This is an open access article distributed under the Creative Commons Attribution License, which permits unrestricted use, distribution, and reproduction in any medium, provided the original work is properly cited.

\section{Introduction}

Laryngeal cancer is the second most common upper aerodigestive cancer, in particular, it causes pain, dysphagia, and impedes speech, breathing, and social interactions.

The management of advanced cancers often includes radical surgery, such as a total laryngectomy which involves the removal of the vocal cords and, as a consequence, the loss of voice. Total laryngectomy represents an operation that drastically affects respiratory dynamics and phonation mechanisms, suppressing the normal verbal communication, it is disabling and has a detrimental effect on the individual's quality of life. In fact, for some laryngectomy patients, the loss of speech is more important than survival itself.

With the laryngectomy, the patient is deprived of the vibrating sound source (the vocal folds and laryngeal box) and the energy source for voice production, as the air stream from the lungs is no longer connected to the vocal tract.

Consequently, since 1980, different methods for regaining phonation have been developed, the most important are (1) the use of an electro-larynx, (2) conventional speech therapy, (3) surgical prosthetic methods [1-3].

The use of an electro-larynx allows the restoration of the voice by an external sound generator; it is exclusively reserved for patients who have not benefited from conventional speech therapy or on whom a tracheoesophageal prosthesis cannot be applied.

The conventional speech therapy allows the acquisition of autonomously oesophageal voice (EV) and, therefore, it is the most commonly used treatment in voice rehabilitation of laryngectomized patients which requires a sequence of training sessions to develop the ability to insufflate the oesophagus by inhaling or injecting air through coordinate muscle activity of the tongue, cheeks, palate, and pharynx. The last technique of capturing air is by swallowing air into the stomach. Voluntary air release or "regurgitation" of small volumes vibrates the cervical esophageal inlet, hypopharingeal mucosa, and other portions of the upper aerodigestive tract to produce a "burp-like" sound. Articulation of the lips, teeth, palate, and tongue produces intelligible speech.

The surgical prosthetic methods (TEP), introduced in 1980 by Weinberg et al. [4], spread rapidly due to the excellent outcomes that they achieved. In this case a phonatory valve is positioned in a specifically made shunt in the tracheoesophageal wall, and closing the tracheostoma, the air reaches the mouth (through the cervical esophageal inlet, hypopharingeal mucosa, and the upper aerodigestive tract) and the vibration is modulated with a new voice production. 
TABLE 1: Patient data, vocal, and pressure parameters.

\begin{tabular}{|c|c|c|c|c|c|c|c|c|c|c|c|c|}
\hline & & Pers & sonal data & & & & ocal param & eters & & & Tracheosto & ma pressure \\
\hline & Age & Sex & $\begin{array}{l}\text { Tracheostoma } \\
\text { area }\end{array}$ & $\begin{array}{l}\text { Fundamental } \\
\text { frecuancy }\end{array}$ & Jitter & $\begin{array}{l}\text { Jitter } \\
\text { perc. }\end{array}$ & Shimmer & $\begin{array}{l}\text { Shimmer } \\
\text { perc. }\end{array}$ & NHR & $\begin{array}{l}\text { Maximum } \\
\text { phonation } \\
\text { time }\end{array}$ & $\begin{array}{l}\text { Tracheostoma } \\
\text { pressure }\end{array}$ & $\begin{array}{l}\text { Acoustic } \\
\text { pressure/ } \\
\text { Tracheostoma } \\
\text { pressure }\end{array}$ \\
\hline & & & {$\left[\mathrm{cm}^{2}\right]$} & {$[\mathrm{Hz}]$} & {$[\mathrm{ms}]$} & {$[\%]$} & {$[\mathrm{Pa}]$} & [\%] & {$[-]$} & {$[\mathrm{s}]$} & {$[\mathrm{Pa}]$} & {$[-] * 10^{(-7)}$} \\
\hline EV1 & 49 & M & 1.56 & 75.188 & 17.67 & 13.44 & 0.00073 & 0.36 & 0.832 & 0.90 & - & - \\
\hline EV2 & 77 & $\mathrm{M}$ & 0.87 & 153.846 & 42.67 & 33.41 & 0.00019 & 0.56 & 3.265 & 0.77 & - & - \\
\hline EV3 & 62 & $\mathrm{M}$ & 1.37 & 96.154 & 33.67 & 18.01 & 0.00026 & 0.43 & 1.063 & 0.65 & - & - \\
\hline EV4 & 60 & M & 1.69 & 56.497 & 13.33 & 24.46 & 0.00026 & 0.21 & 1.575 & 0.68 & - & - \\
\hline EV5 & 74 & M & 1.94 & 69.444 & 28.33 & 21.76 & 0.00005 & 0.19 & 1.297 & 1.63 & - & - \\
\hline EV6 & 71 & M & 0.69 & 98.039 & 22.67 & 22.39 & 0.00048 & 0.83 & 1.032 & 0.68 & - & - \\
\hline EV7 & 61 & M & 0.62 & 56.818 & 30.33 & 25.38 & 0.00006 & 0.15 & 1.146 & 0.57 & - & - \\
\hline TEP1 & 68 & $\mathrm{M}$ & 1.75 & 112.360 & 3.33 & 3.79 & 0.00012 & 0.20 & 0.834 & 48.45 & 4906 & 1.7077 \\
\hline TEP2 & 61 & $\mathrm{~F}$ & 2.37 & 102.041 & 6.00 & 6.13 & 0.00005 & 0.23 & 0.487 & 12.18 & 2960 & 1.0955 \\
\hline TEP3 & 76 & M & 0.68 & 86.957 & 18.67 & 17.06 & 0.00029 & 0.51 & 1.906 & 7.86 & 3752 & 2.0051 \\
\hline TEP4 & 78 & M & 1.62 & 109.890 & 3.33 & 3.86 & 0.00012 & 0.30 & 2.892 & 6.47 & 5077 & 1.6604 \\
\hline TEP5 & 61 & M & 1.44 & 60.606 & 4.67 & 2.86 & 0.00001 & 0.17 & 0.146 & 22.39 & 1790 & 0.3187 \\
\hline TEP6 & 76 & M & 2.21 & 58.590 & 13.67 & 10.99 & 0.00033 & 0.36 & 0.216 & 4.67 & 2481 & 3.9962 \\
\hline TEP7 & 60 & M & 1.00 & 107.527 & 9.00 & 10.41 & 0.00021 & 0.38 & 2.776 & 19.11 & 5127 & 3.2538 \\
\hline
\end{tabular}

The resulting speech depends on the expiratory capacity but the voice quality is very good and resembles the "original" voice. This kind of voice is called "tracheoesophageal" voice. Intelligibility of EV can vary according to several perceptive factors on the precise definition for which there is no general agreement. Furthermore, aerodynamic data in the study of EV physiology and, in particular, correlations between those data and the perceptive findings have not been defined as yet.

The sound generator of both oesophageal and tracheoesophageal speech is the mucosa of the pharyngoesophageal (PE) segment, that differs from patient to patient, depending on the shape and stiffness of the scar between the hypopharynx and oesophagus, the localization of the carcinoma, different surgical needs and procedures, and the extent of the remaining esophageal mucosa. Several investigations of the substitute voice attempted to detect a correlation between voice quality and morphological or dynamic properties of the PE segment [5] but sometimes the method is not very comfortable for the patient.

In this paper, a simple and physiological method of measurement of voice characteristics is presented, useful, above all, for oesophageal and tracheoesophageal voices that are characterised by a strong aperiodicity.

Voice quality is a perceptual phenomenon, and consequently, perceptual evaluations are considered the "gold standard" of voice quality evaluation. In clinical practice, perceptual evaluation plays a prominent role in therapy evaluation, while the acoustic analyses are not usually routinely performed.

Several studies have described acoustic analysis of oesophageal and tracheoesophageal voice quality and have concluded that there is a considerable difference between the laryngeal voice and the acoustic measures, because these voices have a high aperiodicity [6-8].

For this reason a commercially available Multi Dimensional Voice Program (MDVP), suitable for a subject not laryngectomized with laryngeal voice, is not useful to analyze all the tracheoesophageal voices, where the power vocal signal in terms of frequency and the amplitude outline is not regular, with distinguishable peak values and clean sound [6].

\section{Patients}

The subjects included 14 Italian laryngectomized patients (13 men and 1 woman) with ages ranging from 49 to 78 years, with a mean of 66.7 years. Seven of them speak with oesophageal voice (EV) while seven patients have a Provox voice prostheses (TEP).

For each patient a picture of the stoma has been taken to obtain its size (or area). The stoma size ranged from $0.62 \mathrm{~cm}^{2}$ to $2.21 \mathrm{~cm}^{2}$, with a mean of $1.41 \mathrm{~cm}^{2}$.

In Table 1 are shown the personal data of the patients: age, sex, and size of the stoma.

\section{Methods}

3.1. Voice and Tracheostoma Pressure Measurement. The phonetic specialists have a standard method to evaluate the voice characteristics, the first is a perceptive evaluation but the most important is the objective evaluation to measure the acoustic characteristics of the voice using a computerized analysis [9-11]. 
The oesophageal and the tracheoesophageal voice are characterized by aperiodic characteristics and important noise components, so it is very difficult to individuate the peak values. For this reason the use of a multiparameter programme MDVP for these kinds of voices does not provide reliable results, while the programme is very reliable for laryngeal voices; this is pointed out by different research groups $[6,8,11,12]$. In this paper a new different system has been proposed and used, taking into account the knowledge of the engineering signal analysis.

For the research shown in this paper a specific experimental setup has been made by a microphone (Bruel and Kjier, 4133 type, with stabilized supplier 2804 type and preamplifier type 2669) and a digital oscilloscope with a specific setup (Tektronik type) that allows recording of a data sequence.

The measurement and recording of speech signals have been taken with the patient standing up and a microphone positioned $20 \mathrm{~cm}$ from the mouth at an angle of $45^{\circ}$. In this condition, the patient pronounced the vowel $/ \mathrm{a} /$ with a tone and sound level considered by himself to correspond to a usual conversation.

The speech signal was recorded for 1 second to have it constant. In this way, it is possible to consider a steady signal, with average value and variance constants, and with the power spectral analysis it is possible to use the Fourier transform and the Wiener Kintchine theorems. The use of a sampling frequency of $10 \mathrm{kHz}$ allows to evaluate the signal up to a frequency of $5 \mathrm{kHz}$, according to Nyquist theorem.

The maximum phonation time was measured in the same conditions but with the patient that pronounces the vowel /a/ as long as possible.

Every test on each individual patient was carried out three times to verify the repeatability of the measurements, Table 1 reports the mean values.

For the patient with tracheoesophageal voice the speech signal and the pressure at the tracheostoma were recorded simultaneously.

The pressure was measured with a specifically made device. A Provox adhesive plaster (usually used for the stoma filter) positioned on the tracheostoma allows to fix a small teflon cylinder of suitable diameter. A soft rubber part is connected to the other extremity of the cylinder; the patient, using two fingers, closes the rubber part on the tracheostoma.

A pressure transducer (RS Component 235-5790), positioned in a pressure measurement point in radial position on the cylinder, allows a dynamic measurement of the tracheostoma pressure to be taken by means of a digital oscilloscope.

The pressure measurement device is shown in Figures 1(a) and 1(b). In particular, in the case of Figure 1(a) the patient can breath freely; in the case of Figure 1(b) the device can be closed by the patient to allow voice production, in these conditions the pressure and the voice signal are recorded simultaneously using a digital oscilloscope.

The pressure and voice signals have been treated with a program (developed in MATLAB) specifically written to

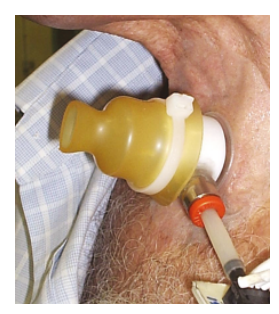

(a)

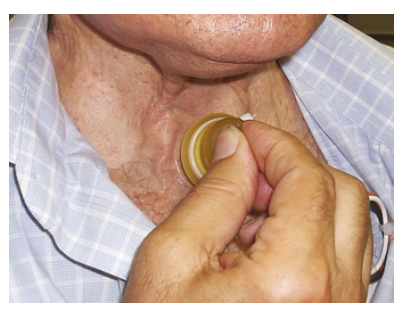

(b)
FIGURE 1: Device for tracheostoma pressure measurement.

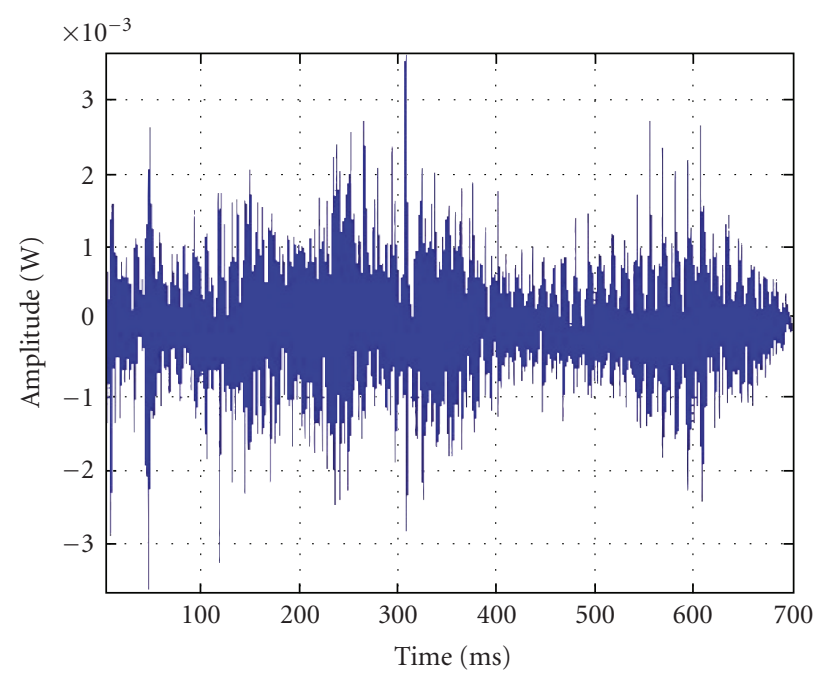

FIgURE 2: Vocal signal amplitude versus time (EV1).

carry out spectral power analysis and based on a decisionmaking tool, to obtain the following:

(i) vocal signal analysis: power spectral density (by Welch period analysis), time-frequency spectrogram (or sonogram); fundamental frequency (cepstrum method); jitter and jitter percentage; shimmer and shimmer percentage, Noise to Harmonic Ratio (NHR);

(ii) tracheostoma pressure signal analysis: power spectral analysis, pressure average value;

(iii) cross-spectral analysis of vocal and pressure signal to point out the same harmonic components;

(iv) acoustic pressure to tracheostoma pressure ratio (ratio of the maximum values).

The tracheostoma pressure allows important information about the "in vivo" pressure necessary to open the phonatory valve to speech, while the ratio of the acoustic pressure to the tracheostoma pressure gives the pulmonary effort level necessary for the patient to produce the voice. In fact it is possible to note that at equal acoustic pressure, a low pulmonary effort is necessary for a subject that has a low tracheostoma pressure. 


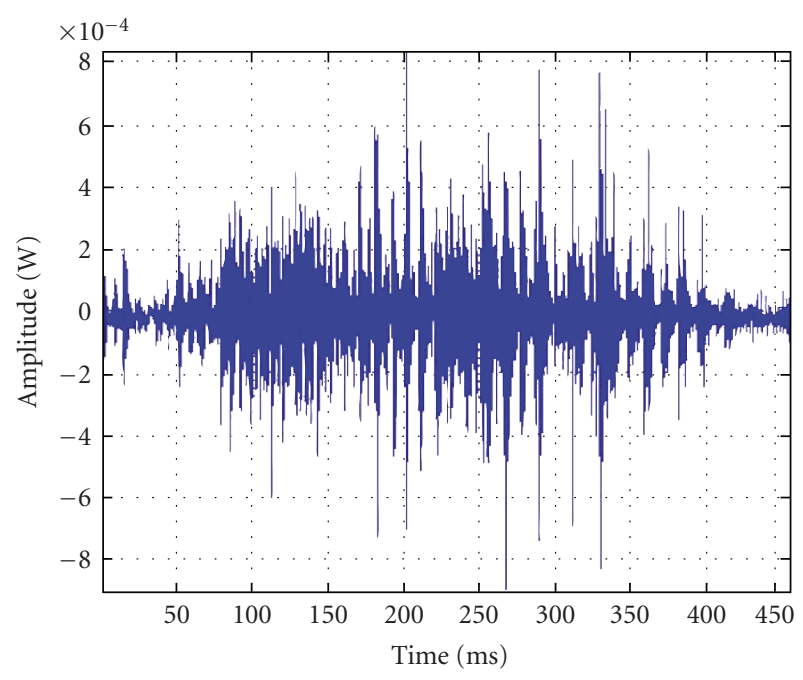

FIgURE 3: Vocal signal amplitude versus time (TEP3).

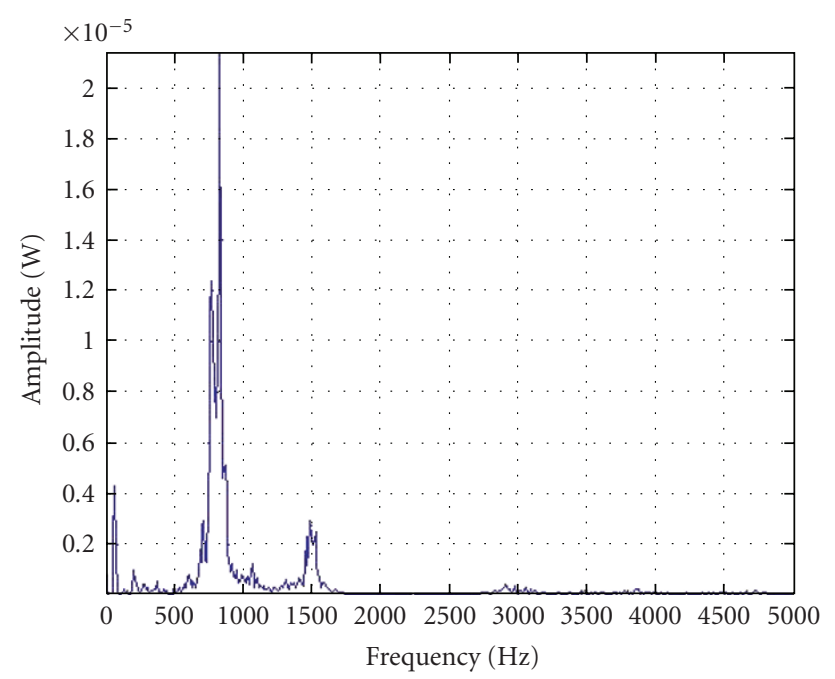

FIgURE 4: Vocal signal amplitude versus frequency (EV1).

Sometimes EV and TEP voice samples could not be analysed at all, or only very short parts were analyzable. Visual inspection of these voice samples showed that the patients had very low-pitched voices (for this reason the use of MDVP system is not suitable) or even that there is no fundamental frequency present at all.

The obtained vocal and tracheostoma pressure parameters are shown in Table 1.

\section{Results and Discussion}

Taking into account the data shown in Table 1 average value and standard deviation $( \pm \sigma)$ was calculated for the two groups of voices (EV and TEP). The results are shown in Table 2; it is possible to note that the tracheoesophageal voices TEP have a lower standard deviation for the vocal parameters (frequency, jitter, shimmer), in fact the TEP voices are more repeatable and have better acoustic

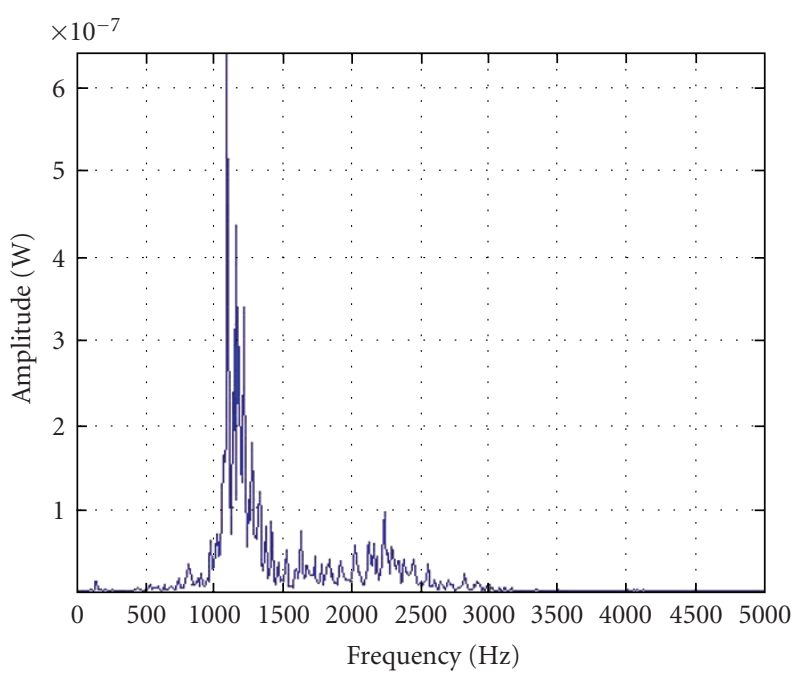

FIGURE 5: Vocal signal amplitude versus frequency (TEP3).

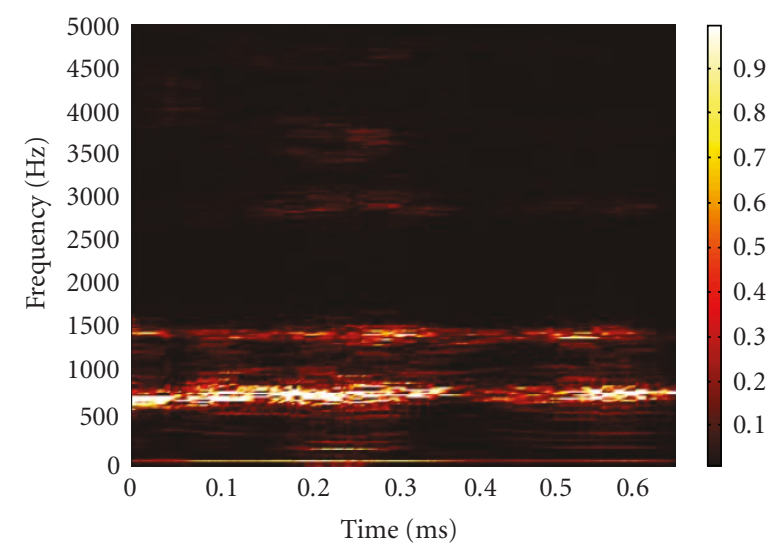

Figure 6: Vocal signal frequency versus time (EV1).

characteristics. The oesophageal voice EV has lower standard deviation regarding the maximum phonation time but it is necessary to note that generally the patients with a TEP voice have longer phonation time and this allows a better way to communicate and quality of the life.

Each patient's voice signal (oesophageal EV and tracheoesophageal TEP) has been recorded and treated with the developed MATLAB program. As an example, the results of concerning two patients, namely, EV1 and TEP3, are shown from Figure 2 to Figure 7.

The recorded signal in term of amplitude versus time is shown in Figures 2 (EV1) and 3 (TEP3).

The spectral power analysis allows to obtain the amplitude as a function of the time or the frequency as a function of the time.

Figures 4 (EV1) and 5 (TEP3) show the amplitude versus frequency spectra. It is possible to note that the esophageal voice EV has one fundamental frequency and a noise component at high frequency level, while the tracheoesophageal voice TEP has a frequency peak value and two noise components. 
TABLE 2: Average and standard deviation for patient data, vocal, and pressure parameters.

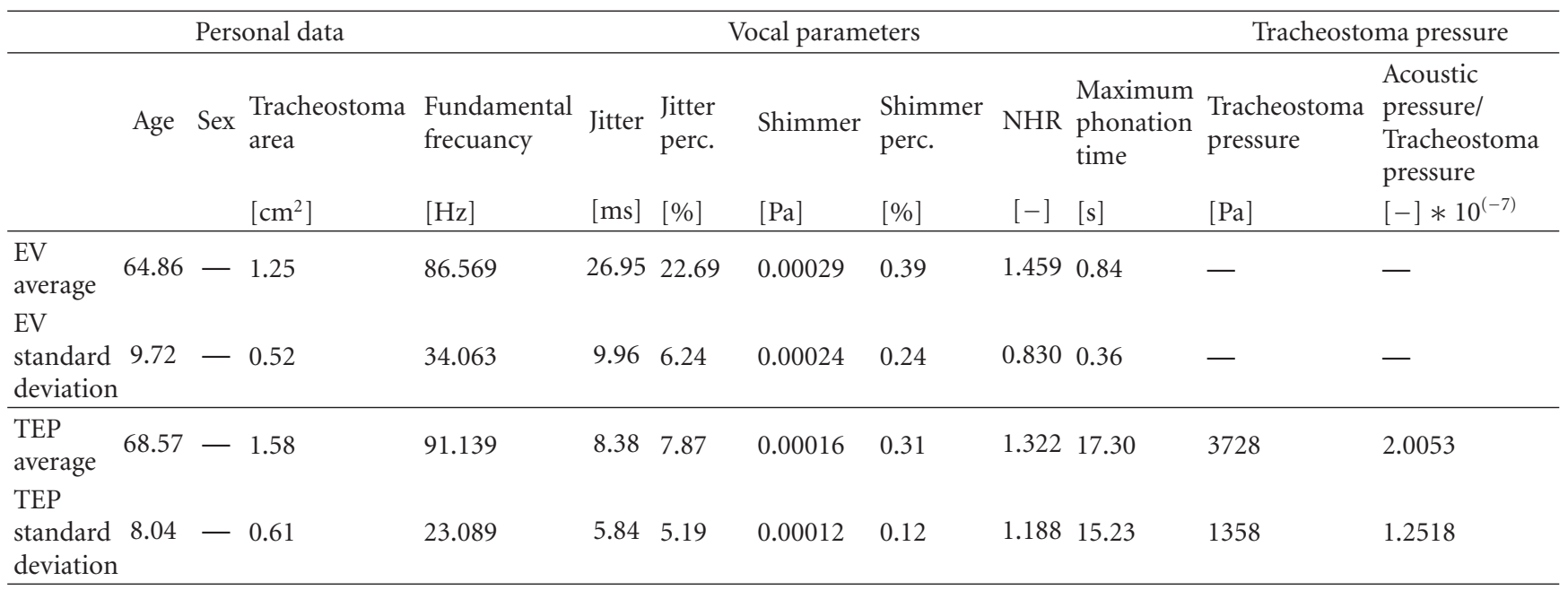

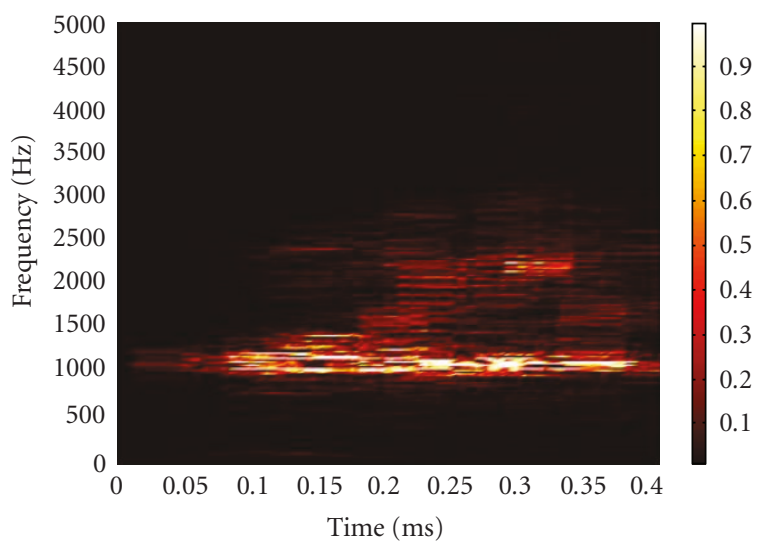

FIgURE 7: Vocal signal frequency versus time (TEP3).

The frequency spectrum in term of frequency versus time behaviour is shown in Figures 6 (EV1) and 7 (TEP3).

Similar behaviour was observed for the other patients. Finally, an overall analysis of the data obtained from the 14 patients was made, pointing out a noise component between $600 \mathrm{~Hz}$ and $800 \mathrm{~Hz}$ in all cases, with a harmonic component between $1200 \mathrm{~Hz}$ and $1600 \mathrm{~Hz}$. This phenomenon could be correlated to pseudo-glottis (or larynx-oesophageal tract) physiological characteristics.

For all the TEP patients the tracheostoma pressure versus time was recorded and the power spectral analysis has been carried out. The results for TEP3 are shown in Figure 8 in term of pressure versus time and in Figure 9 in term of amplitude versus frequency.

To investigate the correlation between the pressure and the voice signals (with TEP subject) the cross-spectrum based on the Fourier transform was evaluated. The most important and interesting result pointed out by this analysis is that the two signals have equal fundamental frequency and the same harmonic components for each TEP subject considered. Figure 10 shows the results obtained with the TEP3.

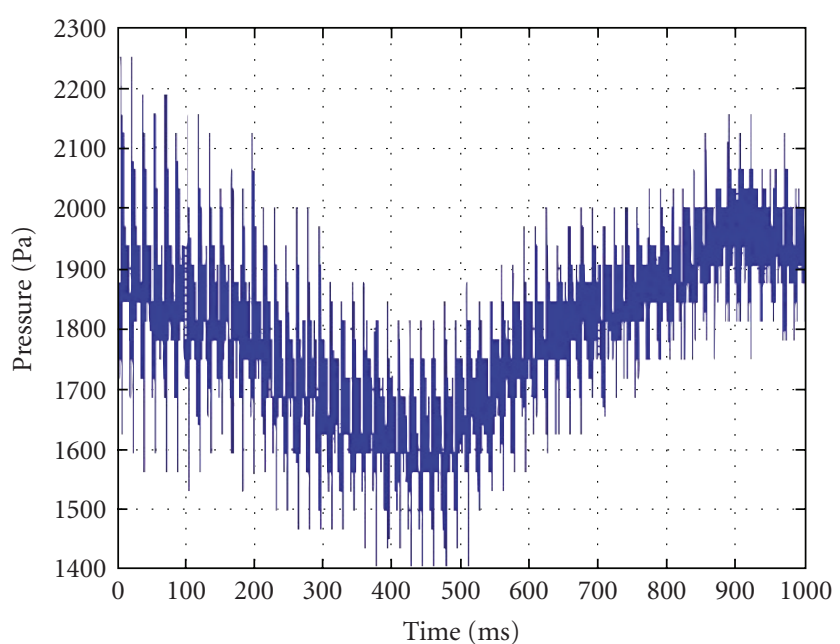

Figure 8: Pressure signal versus time (TEP3).

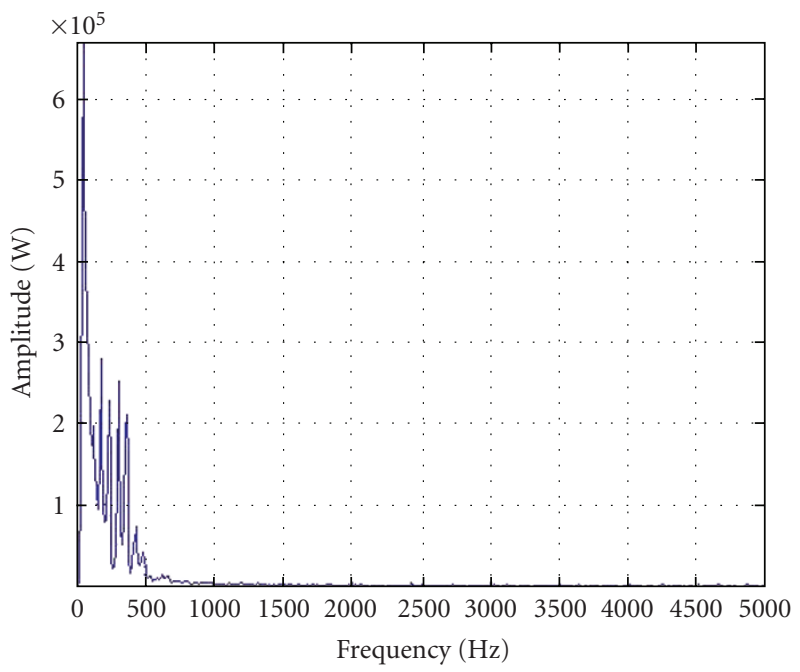

FIgURE 9: Pressure signal amplitude versus frequency (TEP3). 


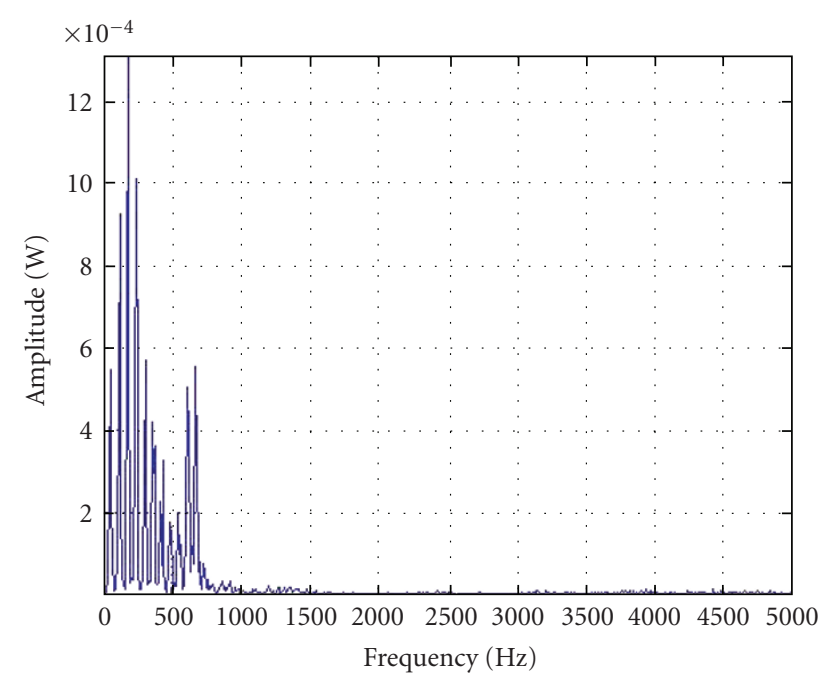

FIgURe 10: Pressure and voice signal amplitudes (cross spectrum) versus frequency (TEP3).

Future steps of this research could be (i) increasing the number of patients to improve statistically the reliability of the analysis; (ii) comparing the tracheostoma pressure before and after the TEP procedure to improve the correlation between voice frequency and tracheostoma pressure after the TEP procedure.

\section{References}

[1] H. F. Mahieu, Voice and speech rehabilitation following laryngectomy, Doctoral dissertation, Rijksuniversiteit Groningen, Groningen, The Netherlands, 1988.

[2] E. D. Blom, M. I. Singer, and R. C. Hamaker, Tracheoesophageal Voice Restoration Following Total Laryngectomy, Singular Publishing, San Diego, Calif, USA, 1998.

[3] G. Belforte, M. Carello, G. Bongioannini, and M. Magnano, "Laryngeal prosthetic devices," in Encyclopedia of Medical Devices and Instrumentation, J. G. Webster, Ed., vol. 4, pp. 229234, John Wiley \& Sons, New York, NY, USA, 2nd edition, 2006.

[4] B. Weinberg, Y. Horii, E. Blom, and M. Singer, "Airway resistance during esophageal phonation," Journal of Speech and Hearing Disorders, vol. 47, no. 2, pp. 194-199, 1982.

[5] M. Schuster, F. Rosanowski, R. Schwarz, U. Eysholdt, and J. Lohscheller, "Quantitative detection of substitute voice generator during phonation in patients undergoing laryngectomy," Archives of Otolaryngology, vol. 131, no. 11, pp. 945-952, 2005.

[6] C. J. van As-Brooks, F. J. Koopmans-van Beinum, L. C. W. Pols, and F. J. M. Hilgers, "Acoustic signal typing for evaluation of voice quality in tracheoesophageal speech," Journal of Voice, vol. 20, no. 3, pp. 355-368, 2006.

[7] C. J. van As-Brooks, F. J. M. Hilgers, F. J. Koopmans-van Beinum, and L. C. W. Pols, "Anatomical and functional correlates of voice quality in tracheoesophageal speech," Journal of Voice, vol. 19, no. 3, pp. 360-372, 2005.

[8] C. J. van As-Brooks, F. J. M. Hilgers, I. M. Verdonck-de Leeuw, and F. J. Koopmans-van Beinum, "Acoustical analysis and perceptual evaluation of tracheoesophageal prosthetic voice," Journal of Voice, vol. 12, no. 2, pp. 239-248, 1998.
[9] W. De Colle, Voce \& Computer, Omega Edizioni, Italy, 2001.

[10] A. Schindler, A. Canale, A. L. Cavalot, et al., "Intensity and fundamental frequency control in tracheoesophageal voice," Acta Otorhinolaryngologica Italica, vol. 25, no. 4, pp. 240-244, 2005.

[11] C. F. Gervasio, A. L. Cavalot, G. Nazionale, et al., "Evaluation of various phonatory parameters in laryngectomized patients: comparison of esophageal and tracheo-esophageal prosthesis phonation," Acta Otorhinolaryngologica Italica, vol. 18, no. 2, pp. 101-106, 1998.

[12] S. Motta, I. Galli, and L. Di Rienzo, "Aerodynamic findings in esophageal voice," Archives of Otolaryngology, vol. 127, no. 6, pp. 700-704, 2001. 